\title{
Demographic parameters of women with uterine fibroids presenting as abnormal uterine bleeding
}

\author{
Manjiri R. Podder ${ }^{1 *}$, Rahul Podder ${ }^{1}$, Poonam V. Shivkumar ${ }^{2}$
}

\begin{abstract}
${ }^{1}$ Department of Obstetrics and Gynecology, Maharishi Markandeshwar Institute of Medical Sciences and Research, Mullana, Ambala, Haryana, India

${ }^{2}$ Department of Obstetrics and Gynecology, Mahatma Gandhi Institute of Medical Sciences, Sevagram, Maharashtra, India
\end{abstract}

Received: 10 May 2018

Accepted: 02 June 2018

\section{*Correspondence:}

Dr. Manjiri R Podder,

E-mail: drmanjiriramteke@gmail.com

Copyright: (c) the author(s), publisher and licensee Medip Academy. This is an open-access article distributed under the terms of the Creative Commons Attribution Non-Commercial License, which permits unrestricted non-commercial use, distribution, and reproduction in any medium, provided the original work is properly cited.

\section{ABSTRACT}

Background: Uterine fibroids are commonest benign uterine tumors. Only about $25 \%$ women with fibroids are symptomatic. Around $70-80 \%$ are discovered incidentally during routine pelvic examination. Using ultrasonography screening, some authors have estimated a cumulative incidence of $70 \%$ in all women by age 50. Symptoms attributable to fibroids are mainly abnormal uterine bleeding (AUB), pelvic pressure, pain, and reproductive dysfunction. Heavy and/or prolonged menses is the typical bleeding pattern with myomas. Uterine fibroids are a leading cause of hysterectomy in perimenopausal women, thus, this study was done to find out its prevalence and demography in women presenting with AUB. The objectives of the present investigation were to find out the prevalence of uterine fibroid in women with AUB and to find out the various demographic features of women

Methods: The study was done for 2 years in the Dept of Obstetrics and Gynecology of a rural tertiary institute after taking clearance from institutional ethical committee. All the women presenting with AUB were included in the study. History and demographic features was enquired and entered in a predesigned proforma. All women were clinically examined after consent. Women with suspicion of fibroid were subjected to diagnostic modalities and the reports were followed and correlated.

Results: Total 11,841 patients came to Gynaeological OPD during the study period. Out of these 3,878 (32.75\%) presented with AUB, 2,126 were diagnosed as having fibroids after examination and investigations. Hence, the prevalence of fibroids amongst the women with AUB was $54.82 \%$ and $17.95 \%$ amongst all gynaecological patients. Maximum women were between 31-40 years, (64.78\% rural and 62.73\% urban). Majority were having parity between $1-2(40.73 \%$ in urban, $38.96 \%$ in rural).

Conclusions: Uterine fibroids are the commonest reason of AUB in reproductive age group with the prevalence of $54.82 \%$. The trends in age incidence have remained the same over the years, commonly affecting women in third decade. There is no difference in incidence of fibroids amongst various socioeconomic classes.

Keywords: Abnormal uterine bleeding, Demography, Reproductive age group, Uterine fibroids

\section{INTRODUCTION}

Uterine fibroids are composed mainly of smooth muscle cells and varying amounts of fibrous connective tissue, and are by far, the most common benign uterine tumors.
Most of them are asymptomatic and very rarely malignant. ${ }^{1-5}$ The size of fibroids ranges from between a seedling fibroid to a huge neoplasm. Other uncommon variants of leiomyomas are leiomyomatosis peritonealis disseminate, intravenous leiomyomatosis and benign 
metastasizing leiomyomas. ${ }^{6}$ Around $70-80 \%$ of leiomyomas are asymptomatic and are discovered incidentally during a routine pelvic examination. ${ }^{1}$ Using ultrasonography screening, some authors have estimated a cumulative incidence of $70 \%$ in all women by age 50 . The incidence is rare before puberty and after menopause.

The exact etiology of fibroid is unknown. Estrogen is implicated in the growth of the myomas as myomas have more estrogen receptors than rest of the myometrium 8 . Progesterone inhibits the growth of myomas. Endometrial hyperplasia, dysfunctional metropathic bleeding and endometrial carcinoma are associated with fibroids in women with hyperestrogenism. There may be genetic predisposition in the development of fibroids. Increase in size is seen during pregnancy and with use of oral contraceptives.

Most women with uterine fibroids are asymptomatic and usually do not require any treatment. ${ }^{9}$ Careful counselling and reassurance are all that is required. Fibroids, particularly when small, may be entirely asymptomatic. Only about $25 \%$ of the women with fibroids present with symptoms. ${ }^{10}$ Symptoms attributable to uterine myomas can generally be classified into three distinct categories: 1) Abnormal uterine bleeding. 2) Pelvic pressure and pain. 3) Reproductive dysfunction.

Abnormal uterine bleeding is the most common symptom. Heavy and/or prolonged menses is the typical bleeding pattern with myomas. ${ }^{9}$ Heavy uterine bleeding may be responsible for associated problems, such as iron deficiency anaemia, social embarrassment, and loss of productivity in the work force. The presence and degree of uterine bleeding are determined, in large part, by the location of the fibroid; size is of secondary importance. Submucosal myomas that protrude into the uterine cavity (e.g., types 0,1,2), are most frequently related to significant menorrhagia. ${ }^{12,13}$ However, women with intramural myomas also commonly experience heavy or prolonged menstrual bleeding.

Other symptoms appear due to pressure from myomas at particular locations. As examples, urinary frequency, difficulty in emptying the bladder, and, rarely, urinary obstruction can all occur with fibroids. Dysmenorrhoea or dyspareunia may also be the presenting symptoms sometimes. Infertility or recurrent abortions may be the presenting symptom in leiomyomas distorting the cavity. In a study by Pritts in 2001, it was found that women with submucous myomas demonstrated lower pregnancy rates and implantation rates than infertile controls. ${ }^{14}$

The diagnosis is made by bimanual pelvic examination, in which the typical finding is enlarged, mobile uterus with an irregular contour. Imaging modalities used for diagnosis include - ultrasound, in which transvaginal USG is more specific. Magnetic resonance imaging (MRI) is the best imaging modality for diagnosis of fibroids as it helps in distinguishing among leiomyomas, ovarian masses, adenomyosis, adenomyomas and leiomyosarcomas, and also helps in planning for surgery in cases of difficult myomas. It also alters the diagnoses and treatment plans of interventional radiologists evaluating women with presumed symptomatic fibroids. ${ }^{15}$

Studies have shown that $30 \%$ to $50 \%$ of all hysterectomies are due to abnormal bleeding and uterine fibroids. Thus, as a leading cause of hysterectomy in premenopausal women, uterine leiomyomas are a major public health problem. ${ }^{16}$. As this is a problem of such a big magnitude, this study was done to find out its prevalence and demography in the study population of women presenting with abnormal uterine bleeding.

The objectives of the present investigation were to find out the prevalence of uterine fibroid in women presenting as abnormal uterine bleeding and to find out the various demographic features of women presenting with abnormal uterine bleeding to the gynaecological department who are clinically, ultrasonographically or by CT / MRI imaging diagnosed to have uterine fibroid.

\section{METHODS}

The study was carried out in the Department of Obstetrics and Gynaecology of a Rural Tertiary Institute. It was done for a period of 2 years (October 2010 - September 2012), wherein all the women who were admitted in the hospital or came in the outpatient department with abnormal uterine bleeding were included in the study. The detailed history in relation to the demographic features was enquired as a routine protocol and all these details were entered in a predesigned proforma.

All these women were clinically examined (especially per vaginal examination) after taking consent. Out of these women, in whom suspicion of fibroid uterus was present were subjected to diagnostic modalities used in the study like ultrasound/CT/MRI or examination under anaesthesia. The reports were followed and were clinically correlated.

The results were compiled using Epi data form from the Excel sheets, which were filled using the proformas. The details were entered in tabular forms and tables were developed using the different variables.

The study was conducted in the gynaecological department of a rural tertiary care institute over a period of 2 years. All the women presenting with abnormal uterine bleeding due to uterine fibroids who gave the consent were included in the study.

\section{Inclusion criteria}

- All symptomatic women of all age groups presenting in the department of Obstetrics and Gynaecology with the history of abnormal uterine bleeding, who were clinically, ultrasonographically or after CT 
/MRI were diagnosed to have uterine fibroids were the cases

\section{Exclusion criteria}

- Women with abnormal uterine bleeding due to other causes, like pregnancy, malignancy or coagulation disorders

- Women who did not give consent.

\section{RESULTS}

Total 11,841 patients came to Gynaecological OPD with different gynaecological complaints during the study period of 2 yrs. Out of these 3,878 (32.75\%) women presented with various forms of abnormal uterine bleeding. Abdominal and bimanual pelvic examination was done and women suspicious of having fibroid uterus were included in the study after taking consent.
Out of those 3,878 women, 2,126 were diagnosed as having uterine fibroids after examination and investigations. Hence, in this study the prevalence of fibroid uterus amongst the women with abnormal uterine bleeding was $54.82 \%$ and $17.95 \%$ amongst all gynaecological patients.

During the study period, there were total 3,418 gynaecological admissions (majority are admitted through OPD). Out of these 1,174 (34.34\%) presented with abnormal uterine bleeding. $616(52.47 \%)$ out of 1,174 women with abnormal uterine bleeding were diagnosed to have uterine fibroid. All these 616 women were seen in OPD.

Thus, the prevalence of fibroid uterus amongst the women with abnormal uterine bleeding was $52.47 \%$ and $19.56 \%$ amongst all the gynaecological admissions.

Table 1: Relationship of age, parity and socioeconomic status in the study of women with fibroid uterus presenting as abnormal uterine bleeding.

\begin{tabular}{|c|c|c|c|c|c|c|c|c|}
\hline & \multirow{2}{*}{$\begin{array}{l}\text { Age } \\
\text { (Years) }\end{array}$} & \multirow[b]{2}{*}{ Parity } & \multicolumn{5}{|c|}{ Socioeconomic status } & \multirow[b]{2}{*}{ Total } \\
\hline & & & $\mathbf{U C}$ & UM & $\mathbf{M}$ & $\mathbf{L M}$ & $\mathbf{L}$ & \\
\hline \multirow{12}{*}{$\begin{array}{l}\text { Rural } \\
(n=1289) \\
64.45 \%\end{array}$} & \multirow{4}{*}{$\begin{array}{l}20-30 \\
(n=103) \\
7.99 \%\end{array}$} & P0 & 1 & 3 & 4 & 2 & 1 & 11 \\
\hline & & P1-P2 & 2 & 7 & 19 & 11 & 5 & 44 \\
\hline & & P3-P4 & 3 & 5 & 16 & 9 & 5 & 38 \\
\hline & & $\geq$ P5 & 0 & 2 & 6 & 2 & 0 & 10 \\
\hline & \multirow{4}{*}{$\begin{array}{l}31-40 \\
(n=835) \\
64.78 \%\end{array}$} & P0 & 9 & 20 & 45 & 27 & 18 & 119 \\
\hline & & P1-P2 & 26 & 48 & 82 & 110 & 66 & 332 \\
\hline & & P3-P4 & 20 & 31 & 77 & 127 & 37 & 292 \\
\hline & & $\geq \mathrm{P} 5$ & 8 & 7 & 25 & 34 & 18 & 92 \\
\hline & \multirow{4}{*}{$\begin{array}{l}41-50 \\
(n=351) \\
27.23 \%\end{array}$} & $\mathrm{P} 0$ & 3 & 2 & 10 & 9 & 11 & 35 \\
\hline & & P1-P2 & 9 & 11 & 56 & 43 & 30 & 149 \\
\hline & & P3-P4 & 10 & 17 & 29 & 51 & 23 & 130 \\
\hline & & $\geq \mathrm{P} 5$ & 2 & 3 & 11 & 15 & 6 & 37 \\
\hline Total & & & 93 & 156 & 380 & 440 & 220 & 1289 \\
\hline$\%$ & & & $7.21 \%$ & $12.10 \%$ & $29.49 \%$ & $34.14 \%$ & $17.06 \%$ & $100 \%$ \\
\hline \multirow{12}{*}{$\begin{array}{l}\text { Urban } \\
(n=711) \\
35.55 \%\end{array}$} & \multirow{4}{*}{$\begin{array}{l}20-30 \\
(n=69) \\
9.70 \%\end{array}$} & P0 & 0 & 2 & 2 & 2 & 3 & 9 \\
\hline & & P1-P2 & 2 & 4 & 8 & 7 & 5 & 26 \\
\hline & & P3-P4 & 2 & 4 & 7 & 9 & 5 & 27 \\
\hline & & $\geq$ P5 & 0 & 1 & 4 & 2 & 0 & 7 \\
\hline & \multirow{4}{*}{$\begin{array}{l}31-40 \\
(n=446) \\
62.73 \%\end{array}$} & P0 & 2 & 6 & 15 & 18 & 17 & 58 \\
\hline & & P1-P2 & 10 & 28 & 55 & 52 & 33 & 178 \\
\hline & & P3-P4 & 10 & 21 & 57 & 41 & 26 & 155 \\
\hline & & $\geq \mathrm{P} 5$ & 2 & 2 & 18 & 21 & 12 & 55 \\
\hline & \multirow{4}{*}{$\begin{array}{l}41-50 \\
(n=196) \\
27.57 \%\end{array}$} & P0 & 1 & 2 & 8 & 7 & 6 & 24 \\
\hline & & P1-P2 & 3 & 10 & 26 & 18 & 16 & 73 \\
\hline & & P3-P4 & 4 & 8 & 23 & 24 & 21 & 80 \\
\hline & & $\geq \mathrm{P} 5$ & 1 & 3 & 7 & 4 & 4 & 19 \\
\hline Total & & & 37 & 91 & 230 & 205 & 148 & 711 \\
\hline$\%$ & & & $5.20 \%$ & $12.80 \%$ & $32.35 \%$ & $28.84 \%$ & $20.81 \%$ & $100 \%$ \\
\hline
\end{tabular}

$\mathrm{UC}=$ Upper class, $\mathrm{UM}=$ Upper Middle Class, $\mathrm{M}=$ Middle Class, LM= Lower Middle Class, L= Lower Class (Kuppuswamy's Classsification, 2009) 


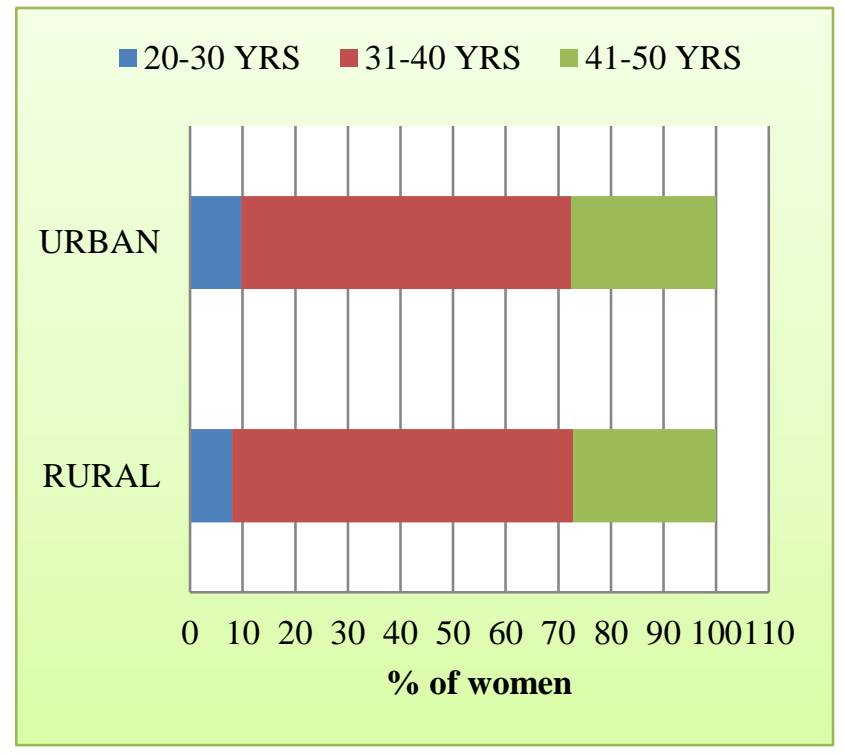

Figure 1: Age distribution graph of women in the study.

Out of the 2,126 women in the study (from OPD+IPD), 126 women were excluded from the study as they were either not willing for participation in the study or did not come for follow up. Hence the study population was of 2000 women.

On looking in to the demographic features, out of the total 2000 cases with fibroid uterus who presented as abnormal uterine bleeding, 1,289 (64.45\%) were from rural population. In this group maximum women, 835 $(64.78 \%)$ were in between the age group 31-40 years, 351 $(27.23 \%)$ were between $41-50$ years of age and 103 (7.99\%) women were between age group 20-30 years. In rural group $165(12.80 \%)$ women were nulliparous, 525 $(40.73 \%)$ were with the parity between $1-2,460$ (35.69\%) with parity between 3-4 and $139(10.78 \%)$ were with parity $\geq 5$.

The total number of women in the urban group was 711 $(35.55 \%)$, out of which $446(62.73 \%)$ women were in age group 31-40 years, $196(27.57 \%)$ between $41-50$ years and $69(9.70 \%)$ women were between $20-30$ years of age. 91 (12.80\%) women were nulliparous, 277 (38.96\%) were with parity between $1-2,262(36.85 \%)$ with parity between $3-4$ and $81(11.39 \%)$ were with parity $\geq 5$ (Table 1). From rural population $440(34.14 \%)$ patients were from lower middle class, $380(29.49 \%)$ patients were from middle class, $220(17.06 \%)$ from lower class where as in urban groups 230 (32.35\%) cases from middle class, $91(12.80 \%)$ cases from upper middle class and 37 $(5.20 \%)$ were from upper class (Table 1$)$. As is evident from the bar diagram, the percentage of women belonging to different age groups was almost equal in both the rural and the urban group, but majority of the women $(64.78 \%$ in rural and $62.73 \%$ in urban group) were belonging to the age group of 31-40 yrs (Figure 1).

\section{DISCUSSION}

Uterine fibroids are the commonest benign uterine tumors and it is estimated that they occur in $20-40 \%$ of women during their reproductive years. ${ }^{2,11}$ Fibroids may occur at any age usually from menarche till menopause but become most evident during reproductive period. The peak age of incidence is during $35-45$ years of age. ${ }^{17}$ They can cause a wide range of clinical symptoms such as heavy menstrual periods, pressure symptoms to surrounding organs and fertility problems. ${ }^{18}$ As a result, surgery for uterine fibroids is common, and in both the UK and USA fibroids are the primary indication for hysterectomy. ${ }^{19,20}$ Whether fibroids are symptomatic or not depends primarily on their size and on their position in relation to the uterine cavity. ${ }^{21}$ Although the definitive management of gynecological symptoms attributable to uterine fibroids is surgical removal, many women decline surgery or prefer to pursue medical management. The natural history of fibroids is poorly understood, which makes it difficult to advise asymptomatic women with fibroids on the risk of developing clinical symptoms in the future. It is well known, however, that fibroids are sensitive to circulating estrogens, which will either cause them to grow or to maintain their size. ${ }^{22}$ It is less clear whether the growth of fibroids is affected by factors other than ovarian steroid hormones. One of the most common symptom of fibroids is abnormal uterine bleeding (AUB) which is responsible for as many as one-third of all outpatient gynecological visits, with the majority of cases just after menarche or in the perimenopausal period. ${ }^{23}$ This is the most distressing symptom, leading the women to seek medical care. Treatment of fibroids must be individualized based on considerations like the presence and severity of symptoms, the patient's desire for definitive treatment, the desire to preserve childbearing capacity, the importance of uterine preservation, infertility related to uterine cavity distortions, and previous pregnancy complications related to fibroid tumors. According to this, decision for medical or surgical management should be taken.

Thus, this study has been carried out in the Department of Obstetrics and Gynaecology of a Tertiary Institute to evaluate the prevalence of uterine fibroids and to study the various demographic parameters in the women with uterine fibroid, who presented with abnormal uterine bleeding. The sample size was 2000 women.

Out of total 11,841 patients who came to Gynaecological OPD, $32.75 \%$ women presented with various forms of abnormal uterine bleeding. Out of these $54.82 \%$ were diagnosed as having uterine fibroids. In a study conducted by Wise et al, the incidence rate of uterine fibroids in all the women included in their study was $34.4 \% .^{24}$ The results of present study show higher incidence of fibroids due to the fact that we have included in present study only those women who presented with abnormal uterine bleeding. 
In a study done by Okolo et al, they have found that the lifetime risk of developing fibroids in woman over the age of 45 years is more than $60 \% .{ }^{25}$ In a study done on Indian population by Diwakar et al, it was found that by 50 yrs of age the prevalence of fibroids is $50 \% .^{26}$

In present study $64.45 \%$ women were from rural and $35.55 \%$ women were from urban population. The literature does not state significant differences between incidence of fibroids in rural and urban population. Majority of women belong to rural area in present study as the tertiary care centre is situated in a rural area and it is also a referral centre for nearby rural areas.

In present study, in rural group maximum women i.e. $64.78 \%$ were in between the age group 31-40 years, and $40.72 \%$ were with the parity between $1-2$. Similarly, in the urban group $62.73 \%$ women were in age group 31-40 years, and $38.95 \%$ were with parity between $1-2$.

The study shows that uterine fibroids are generally seen in the age group 31-40 years. And maximum number of women were with parity between 1-2. Thus, low parity and this age group is most vulnerable.

According to Dawn, 1990 the peak age of incidence of leiomyoma is between 35-45 years of age 17 which is consistent with present study. On comparing present results with other studies authors found that Gupta et al in 2003 found that the occurrence of uterine fibroids was maximum between 21 - 50 years of age although no age is a bar, and in their study, $55.30 \%$ patients were between 36 - 50 years of age. ${ }^{27}$

Baird et al, in their study found that by age 35 the incidence of leiomyomas was $60 \%$ among AfricanAmerican women; the incidence increased to over $80 \%$ by age $50 .^{3}$

According to Sato et al, the risk of leiomyoma increased as the number of births decreased. Also increased time since last birth was associated with increased risk in women with large myomas. ${ }^{28}$

In a study done by Ibrar et al, it was concluded that multiparous patients have fibroids more frequently than nulliparous in their perimenopausal years, which shows their characteristic slow growth rate. ${ }^{29}$ Their findings are consistent with present results.

In present study, the major chunks of rural women were from lower middle class constituting about $34.14 \%$, whereas in urban group $32.35 \%$ cases were from middle class. Although no variations have been seen in relation to socioeconomic class and development of fibroids, Becker et al identified an inverse relationship between income and hysterectomy rates and concluded that impact of nonclinical factors should be considered before taking treatment decisions for patients with uterine fibroids. ${ }^{30}$

\section{CONCLUSION}

Uterine fibroids are the most common benign tumors of the pelvis. In present study the prevalence of abnormal uterine bleeding was found to be $32.75 \%$, and the prevalence of fibroids in total study population was $17.95 \%$. The prevalence of uterine fibroids in women presenting with abnormal uterine bleeding was $54.82 \%$, thus making it the commonest reason of abnormal uterine bleeding in reproductive age group. The trends in age incidence have remained the same over the years as mentioned in the literature. The occurrence of fibroids is rare before 20 yrs of age, and they cease to grow after menopause, thereby commonly affecting women of childbearing age. In present study it was most commonly seen in the third decade in about $64.05 \%$. No case was seen below $20 \mathrm{yrs}$. There is no difference in incidence of fibroids amongst various socioeconomic classes. Although fibroid is a disease of low parity, it was most commonly seen between 1-2 parity in present study $(40.10 \%)$.

\section{ACKNOWLEDGMENTS}

Authors would like to acknowledge the contribution the contribution of the patients included in the study.

Funding: No funding sources

Conflict of interest: None declared

Ethical approval: The study was approved by the Institutional Ethics Committee

\section{REFERENCES}

1. Lesley L, Rock J. Leiomyomata uteri and myomectomy.Te Lindes's operative gynecology. $10^{\text {th }}$ ed. 2011; lippincott, williams and wilkins: 687-726.

2. Wallach E, Vlahos N. Uterine myomas: an overview of development, clinical features, and management. Obstet Gynecol. 2004;104(2):393-406.

3. Baird DD, Dunson DB, Hill MC, Cousins D, Schectman JM. High cumulative incidence of uterine leiomyoma in black and white women: ultrasound evidence. Am J Obstetr Gynecol. 2003;188(1):100-7.

4. Buttram V, Reiter R. Uterine leiomyomata: etiology, symptomatology, and management. Fertil Steril. 1981;36(4):433-45.

5. Serden S, Brook P. Treatment of abnormal uterine bleeding with the gynecologic resectoscope. J Reprod Med. 1991; 6(10):697-9.

6. Ip PP, Cheung AN, Clement PB. Uterine Smooth Muscle Tumors of Uncertain Malignant Potential (STUMP): A Clinicopathologic Analysis of 16 Cases. Am J Surg Pathol. 2009;33(7):992-1005.

7. Ryann Louie A, Armstrong JA, Findeiss LK, Goodwin SC. Comparison of sexual dysfunction using the Female Sexual Function Index following surgical treatments for uterine fibroids. Case Reports Obstetr Gynecol. 2012;2012. 
8. Chrapusta S, Konopka B, Paszko Z, Sieinski W, Szamborski J. Immunoreactive and estrogen-binding estrogen receptors, and progestin receptor levels in uterine leiomyomata and their parental myometrium. Eur J Gynaecol Oncol. 1990;11(4):275-81.

9. Agdi M, Tulandi T. Minimally invasive approach for myomectomy. Semin Reprod Med. 2010;28(3):22834.

10. Nyapathy V, Polina L. MRgFUS treatment of uterine fibroid in a nulliparous woman with acute retention of urine. J Radiol Case Rep. 2012;6(2):1-8.

11. Ryan G, Syrop C, Van Voorhis B. Role, epidemiology, and natural history of benign uterine mass lesions. Clin Obstet Gynecol. 2005;48(2):31224.

12. Buttram V, Reiter R. Uterine leiomyomata: etiology, symptomatology, and management. Fertil Steril. 1981;36(4): 433-45.

13. Wamsteker $K$, Emanuel $M$, de Kruif $H$. Transcervical hysteroscopic resection of submucous fibroids for abnormal uterine bleeding: results regarding the degree of intramural extension. Obstet Gynecol. 1993;82(5):736-40.

14. Pritts E. Fibroids and infertility: a systematic review of the evidence. Obstet Gynecol Surv. 2001;56(8):483-91.

15. Omary RA, Vasireddy S, Chrisman HB, Ryu RK, Pereles FS, Carr JC, et al. The effect of pelvic MR imaging on the diagnosis and treatment of women with presumed symptomatic uterine fibroids. J Vascular Intervent Radiol. 2002;13(11):1149-53.

16. Cramer S, Patel A. The frequency of uterine leiomyomas. Am J Clin Pathol. 1990;94(4):435-8.

17. Dawn CS. Benign Tumors of the genital tract. Textbook of gynaecology and contraception. $10^{\text {th }}$ ed 1990:365-394.

18. Parker WH. Etiology, symptomatology, and diagnosis of uterine myomas. Fertil Steril. 2007;87(4):725-36.

19. Marshall LM, Spiegelman D, Barbieri RL, Goldman MB, Manson JE, Colditz GA, Willett WC, Hunter DJ. Variation in the incidence of uterine leiomyoma among premenopausal women by age and race. Obstetr Gynecol. 1997;90(6):967-73.
20. Vessey MP, Villard-mackintosh LA, Mcpherson K, Coulter A, Yeates D. The epidemiology of hysterectomy: findings in a large cohort study. BJOG: Int J Obstetr Gynaecol. 1992;99(5):402-7.

21. DeWaay DJ, Syrop CH, Nygaard IE, Davis WA, Van Voorhis BJ. Natural history of uterine polyps and leiomyomata. Obstetr Gynecol. 2002;100(1):3-7.

22. Blake RE. Leiomyomata uteri: hormonal and molecular determinants of growth. J Natl Med Assoc. 2007;99(10):1170-84.

23. Awwad J, Toth T, Schiff I. Abnormal uterine bleeding in the perimenopause. Int $\mathbf{J}$ Fertil Menopausal Stud. 1993; 38(5):261-9.

24. Wise LA, Palmer JR, Stewart EA, Rosenberg L. Age-specific incidence rates for self-reported uterine leiomyomata in the Black Women's Health Study. Obstetr Gynecol. 2005;105(3):563.

25. Okolo S. Incidence, aetiology and epidemiology of uterine fibroids. Best Pract Res Clin Obstet Gynaecol. 2008; 22(4):571-88.

26. Divakar H. Asymptomatic uterine fibroids. Best Pract Res Clin Obstet Gynaecol. 2008;22(4):643-54.

27. Gupta G, Gupta N, Singh V, Bisht D. Uterine Fibroids: A Clinical Study with USG Follow-up. Natl J Homoeopathy. 2003;5(3).

28. Sato F, Miyake H, Nishi M, Kudo R. Fertility and uterine size among Asian women undergoing hysterectomy for leiomyomas. Int J Fertil Women's Med. 2000;45(1):34-7.

29. Ibrar F, Riaz S, Dawood NS, Jabeen A. Frequency of fibroid uterus in multipara women in a tertiary care centre in Rawalpindi. J Ayub Med Coll Abbottabad. 2010;22(3):155-7.

30. Becker ER, Spalding J, DuChane J, Horowitz IR. Inpatient surgical treatment patterns for patients with uterine fibroids in the United States, 1998-2002. J Natl Med Assoc. 2005;97(10):1336.

Cite this article as: Podder MR, Podder R, Shivkumar PV. Demographic parameters of women with uterine fibroids presenting as abnormal uterine bleeding. Int J Reprod Contracept Obstet Gynecol 2018;7:2915-20. 